\title{
A PROPOSED FRAMEWORK BETWEEN INTERNAL, EXTERNAL AND PEDAGOGY DIMENSIONS IN ADOPTION OF INTERACTIVE MULTIMEDIA E-LEARNING
}

\author{
Fathia LAHWAL \\ College of Computing \\ De Montfort University, Leicester, United Kingdom
}

Ajlan S. AL-AJLAN

College of Business \& Economics

Qassim University, Buraidah, Saudi Arabia

Mohamad AMAIN

College of Computing

De Montfort University, Leicester, United Kingdom

\section{ABSTRACT}

This study focuses on interactive multimedia e-learning aims to improve our understanding about the dynamics of e-learning. The objective is to critical evaluate and better understand the interrelationships in the proposed framework between internal, external and the pedagogy dimensions in adoption of interactive multimedia and e-learning. It develops a tool to measure creative user adoption of interactive multimedia and e-learning services by using Partial Least Squares algorithm as the method of estimation and the major analytical tool in this study. Finding of a small scale data sampling of students in United Kingdom indicate that the proposed measurement framework is an acceptable fit with the data. Overall, the findings supply a precise tool for measuring creative user adoption of interactive multimedia and e-learning services, providing further insights for researchers and may provide to guide research and practice in interactive multimedia and e-learning by using communication media.

Keywords: External adoption, internal adoption, pedagogy, multimedia and e-learning.

\section{INTRODUCTION}

The need for integrated pedagogical to enhance Interactive Multimedia E-learning Environment (IMEE) has recently emerged as a priority area in supporting creative user. The fusion of various types of media in interactive e-learning environment, particularly for programming tasks, has generated intense interest, both in UK higher education and international (Heilesen \& Josephsen, 2008). Its potential has recently been demonstrated in the context of enhancing technical skills for creative user in virtual world, by the combination of a variety of interactive multimedia application. However, institutions need to understand which factors may influence and attract creative users to adopt Interactive Multimedia E-learning (IME) for learning programming language, so that can support creative users in acquiring technical skills. Pedagogical has been seen as a key factor in successful and one is adopted in the design. In order to understand how educations and institutions can maintain good or successful a priority with creative user and attract them to use IME to learn programming language, diffusion innovation theory (Rogers, 1995) and the 3P model of learning (Biggs, and Moore, 1993) can be used as a basic for this study.

The main aims of this paper are: (1) to better understand the interrelationship among the internal dimension variables, external dimension variables and pedagogical side variables of students on their perceptions regarding the process of IMEE and furthermore on the effectiveness of IME be adapted by creative user, (2) to find out how pedagogical factors can be 
mediator or moderator the effect of the Internal dimension factors and external dimension factors in the perception of IMEE and furthermore on the effectiveness of IME to be adapted by creative user, (3) to discover which of external dimension factors can best mediate the effects of the student perception (Internal dimension) regarding the process of IME and furthermore on the effectiveness of e-learning to be adapted by creative user, (4) to discover which of pedagogical factors can best mediate the effects of the student perception (Internal dimension) regarding the process of interactive multimedia e-learning and furthermore on the effectiveness of e-learning to be adapted by creative user, (5) to discover which of external dimension factors can best mediate the effects of the student perception (Internal dimension) regarding the process of interactive multimedia e-learning and furthermore on the effectiveness of e-learning to be adapted by creative user and (6) to understand more the dynamics of IME and find out how these factors can be different across different systemic level contexts.

Our interest is to explore the design of robust instrument from a blend of theories of technology models and trust for measuring creative user adoption of e-learning services. Thus, the rest of this paper is organized as follows: First section focuses on the related theories of adoption, primarily via a literature review examining technology acceptance models, Pedagogy in elearning and online environment studies. This is then followed by an introduction to the measurement model intended for the purposes of this study. Then the explanation and justification of the research method is presented. Finally, we conclude the study's overall findings followed by a discussion and future work for both practitioners and researchers respectively.

\section{THEORETICAL FOUNDATION}

This section aims to obtain the key internal, external and pedagogical determinants in order to create a strong tool. This research proceeds primary with the most commonly established theoretical models in the literature of IT acceptance and pedagogical framework followed by interactive multimedia and e-learning related studies.

The theoretical comes up to technology acceptance consist of the Diffusion of Innovation Theory (DOI), Technology Acceptance Model (TAM), and the Theory of Causal Layered Analysis (CLA). The research builds on these to classify the related determinants of the adoption phenomenon and lead the research to the design of a well build up tool.

\section{Adoption of Interactive Multimedia and E-Learning}

Rogers' modelled a useful framework for studying the adoption process. Many studies of diffusion found that the way targeted adopters perceive the attributes of an innovation is critical and that these perceptions account for $49-87 \%$ of the variance in whether or not they adopt. Five significant concepts in the perceived attributes of innovations are (Rogers, 1995):

$>$ Relative advantage: represents the additional benefit offered by the innovation in comparison with the existing offer on the market. The degree of relative advantage is often expressed as economic profitability, social prestige, and other benefits.

$>$ Compatibility: the degree to which an innovation is perceived as consistent with the existing values, past experiences and needs of potential adopters.

$>$ Complexity: the degree to which an innovation is perceived as relatively difficult to understand and use. The more simplistic and less complex the innovations is, the easier it is for someone to adopt.

$>$ Observability: the degree to which the results of an innovation are visible to the society at large, or in a social/professional group. If the observed effects are perceived to be small or non-existent, then the likelihood of adoption is reduced.

> Trialability: The capacity of potential clients to interact with the innovation. This may include trying out parts of a program or having the opportunity to watch others using a new program. 
The 3p Model: Learning Experiences, Process and Effectiveness Model

The 3P model of learning been developed by Biggs and Moore (1993). The 3P's stand for presage, process and product. The pre-existing student variables and contextual and situational issues are the main components of presage section. Student's perceptions regarding their learning environment are assessed under the process part. These perceptions influence students' preferences of learning strategies and how these approaches are implemented. The performance outcomes of the students in the product section (Biggs, Moore, 1993). Examples of representative variables are illustrated in Table 1 , that can be used in learning models within each part.

Table: 1

The 3P model of student learning

\begin{tabular}{ll}
\hline Presage & $\begin{array}{l}\text { Student variables, intellectual capability (IC) and abilities, prior } \\
\text { knowledge, subject area, teaching methods, personality, culture, home } \\
\text { background, time constraints, course structure. }\end{array}$ \\
\hline Process & Student motivation and behavior, Student learning strategies. \\
\hline Product & Exam results, self-concept, grade point average, satisfaction \\
\hline
\end{tabular}

Current research uses a modified version of Biggs and Moore (1993) model to evaluate these relationships among internal dimension factors, external dimension factors and pedagogical of students on their perception about the process of interactive multimedia elearning and furthermore on the effectiveness of interactive multimedia e-learning environment that affect creative user' decision of the adoption.

Interactive Multimedia and E-Learning Studies and Related Research

Studies of latest research have investigated the prospective features that impacts student adoption of e-learning. Biggs and Moore (1993) study adopted Rogers's diffusion of innovation theory (DOI), to find out the essential features that impacts the individuals adoption of e-learning between adult workers in Jordan. The results demonstrated that flexibility, relative advantage, complexity, compatibility, culture, structure, top management support, professional advancement, social contact, external expectations, and social stimulation were greatly correlated to individual's adoption of e-learning initiative. The suggestion is that the features of relative advantage required to be given more highlighting in the adoption of e-learning between individuals (Al-Zoubi, et.al, 2011).

Duan et.al, (2010) study aims to examine an innovation adoption perspective, Chinese students' intention of taking up e-learning degrees. Research hypotheses were established based on Rogers's theory. Five innovation adoption attributes suggested by Rogers were modified in the context of e-learning and were used in the survey questionnaire design and data analysis. The study confirmed that only perceived compatibility has significant positive influences on the students' intention of taking up e-learning degrees, which is in line with a number of other innovation adoption studies concerning the significance of compatibility.

Hsiu-Li et.al, (2008) conducted an empirical research to explore the relevant factors of adoption in the context of e-learning services among students of Taiwan. They administered a survey questionnaire included a combination of items derived from earlier studies and newly developed items to one hundred and thirty seven young respondents aged from $\mathbf{2 0}$ to $\mathbf{3 0}$ years old. The findings showed that perceptions of relative advantage and compatibility are significant relationships with their adoption intention. The results are generally consistent with prior research about other technology adoption. In this study, previous e-learning experiences, compatibility and result demonstrability have a significant, direct effect on user's intention of continued use. However, for users without previous experience of using e-learning, compatibility, image and relative advantage have a significant, direct effect on user's intention of adoption.

Liaw (2008) study investigates learners' satisfaction, behavioral intentions, and the effectiveness of the Blackboard e-learning system among students in university central 
Taiwan. The study integrates multidisciplinary perspectives that included motivation; social cognitive theory (SCT), theory of planned behavior (TPB), and technology acceptance model (TAM). The findings showed that learners' characteristics will influence learners' perceived satisfaction, and perceived usefulness of a product.

By utilizing the theory of technology acceptance model, flow theory and the theory of media richness, Liu et.al, (2009) develop an integrated theoretical model to investigate users' acceptance of streaming media for e-learning by who are both learners and system users. The study proposes three typical groups of presentation types of e-learning that impact users' perceptions: text with auditory, video with supplementary audio, and audio-video by way of a display of corresponding text. The investigation carried out a random sampling to allocate student to three groups .Subjects in all groups were offered access to a module of self-study e-learning system. Between the three groups test only the presentation form of the streaming media for e-learning was varied. After finishing the complete sessions, the subjects who done all four weeks sections of the course were invited to fill in the survey again. It yielded 88 usable responses, giving an overall net response rate of $73 \%$. The results of this study showed that all constructs have a reasonable reliability and validity. These results have practical suggestions for those concerned in adding streaming media into e-learning.

Finally, (Roca, et.al, 2006; Sanchez \& Hueros, 2010) study considered decomposed technology acceptance model in the context of an e-learning services. Based on theoretical background such as TPB, TAM, EDT and users' satisfaction they propose a research framework which identifies several attributes as likely predictors of e-learning continuance intention. The results from this study suggest that ease of use, playfulness and usefulness are considered important issues in IT usage.

In the earlier discussed study of Duan et.al, (2010), it is significant to note that the targeted sample was young students enrolled as a full time undergraduate in a chins university, which confines the results from being generalized to either whole or other population, such as mature students and part time. Liaw (2008) stress the significance of considering perceived satisfaction, behavioral intention, and effectiveness of e-learning factors for a better understanding of the phenomenon. (Liaw, 2008; Roca, et.al, 2006) rightly incorporate in their studies these behavioral intention factors. However, effectiveness of e-learning factors were not included in Roca, et.al, (2006) studies. In contrast, Liaw (2008) represent that the effectives of e-learning can be influenced by multimedia instruction, interactive learning activities, and elearning system in his study in one entity; however, dividing trust into two dimensions, i.e. trust in Internet and government should provide a better explanation for the relevant factors of adoption.

\section{An Integrated Measurement Framework}

This research is based on a combinations of pedagogical strategies Ryberg (2007) with Heilesen and Jensen' frame that consists of internal and external dimensions (Heilesen, Josephsen, 2008). These two dimensions were initially modified by Heilesen, \& Josephsen, (2008) by combing diffusion theory Rogers (1995) with a little modified version of Causal Layered Analysis (CLA) (Inayatullah, 2003). Current study centers around the combination of pedagogical strategies Ryberg (2007), with the external dimension that can be measured and quantified, and an internal dimension, the perception, that is relative to individual (Heilesen, Josephsen, 2008). We believe that these three dimensions influence student perceptions regarding the process of learning environment and furthermore on the effectiveness IMEE which is shown in the IME Adoption Model as in Fig. 1. To investigate factors that have influenced creative user's adoption decision, we focus on three major dimensions as the central construct; namely: 1) Internal dimension, 2) External dimension and 3) Pedagogical side. 


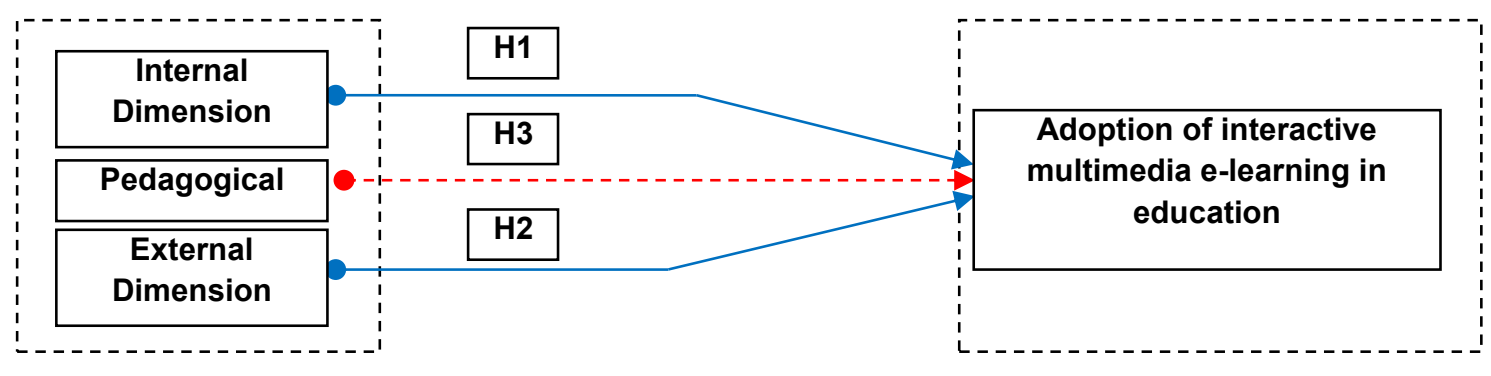

Figure: 1

The Core Hypothesized Framework

Internal dimension: For the internal dimension, current study adapted Biggs' three constructs, student variables, prior knowledge, intellectual capability (IC) and ability, to match internal dimension on current research framework. We call our modified constructs (1) prior educational and knowledge (2) skills and experiences, and (3) characteristic of the student and ability.

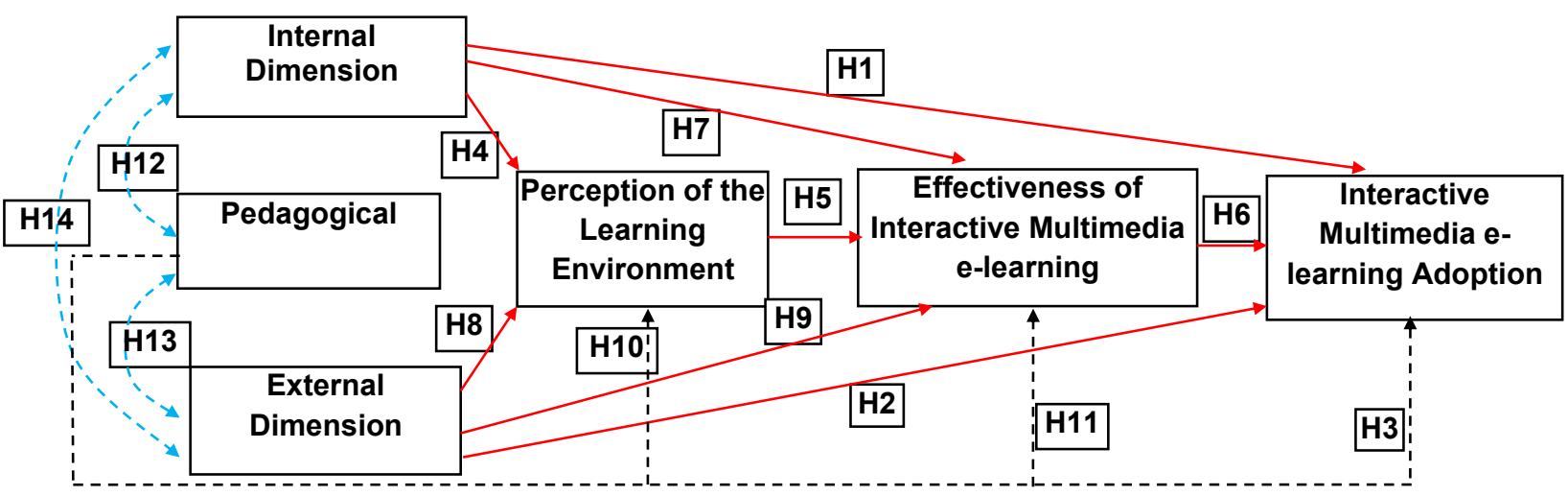

Figure: 2

The Core Hypothesized Framework

We believe that these three constructs influence student perception regarding the process of learning environment and furthermore on the effectives of IMEE which is shown in detailed internal dimensions model Fig. 2 that can be adapted by creative user. Therefore, to further clarify such relationship, the first hypothesis is developed as:

H1: There are multiple features for each of the three constructs as in Fig. 2. For example, for prior educational and knowledge, there are features such as academic specialization; student attitude, and prior of the value of interactive multimedia e-learning. For skills and experiences of the student, facets include experiences.

External dimension: This study centers around the five factors of Heilesen' external dimension: (1) technology supported learning (2) physical (3) economic implication (4) culture setting (5), and social. We believe that these five factors influence student perception regarding the process of learning environment and furthermore on the effectives of IMEE which is shown in detailed internal dimensions model to be adapted by creative user as Fig. 1. So, to further clarify such relationship, the first hypothesis is developed as: 
H2: External Dimension will significantly influence on the perception of the learning environment, furthermore, in the effectiveness of the IMEE to be adapted by creative user.

Pedagogy Strategies; it is based on Ryberg' perspective of learning processes (Ryberg, 2007). Ryberg (2007) developed the model that was argued those three central dimensions of PBL/POPP that could be extracted. Our pedagogy side centres on Problem Based Learning approach as a wide concept to cover a broad range of more student centred learning approaches that feature processes of enquiry, and with a focus on critical knowledge production and distribution, experientially based pedagogy favoring learning as knowledge construction through collaboration in groups and through problem-orientation rather than the acquisition of a given body of knowledge ( Ryberg, 2007).

We believe that these four constructs influence student perception regarding the process of IMEE and furthermore on the effectives of IMEE which is shown in detailed pedagogy strategy of IME adoption model. Thus, the following hypothesis is posted:

H3: Pedagogical dimension with internal and external dimensions will significantly influence on the perception of the learning environment, furthermore, in the effectiveness of the IMEE.

H4: Pedagogical dimension will significantly moderator the internal and external dimensions on the perception of the learning environment, furthermore, in the effectiveness of the IMEE.

H5: Pedagogical dimension will significantly mediator the internal and external dimensions on the perception of the learning environment, furthermore, in the effectiveness of the IMEE to be adapted by creative user.

\section{RESEARCH METHOD}

\section{The Construction of Research Tool}

A questionnaire, the IME Questionnaire (IMeLQ), was developed by the researchers for use in this research to gather data on creative user adoption of IMEE for empirical analysis. It contained closed-ended Likert five-point scale items 1 (Completely disagree) to 5 (Completely agree), open-ended question items and demographic items. The chosen constructs were operationalized using validated items from previous studies. These items were adapted for e-learning services. Therefore, the IMeLQ contained the following four main parts: (1) Internal Dimension, (2) Pedagogical, (3) External Dimension (4) Demographic Information.

The internal dimension examines the personal attitude values experience, and ability and interest that corresponding to compatibility perceived attributes of innovations was adopted from Everett (Duan, et.al, 2010; Haverila, 2010; Haverila, \& Barkhi, 2009), who used the instrument developed by Biggs and Moore (1993 ).

In pedagogy dimension the items that represent content of the instructional design were adopted from Debevc, \& Bele, (2008), who used the instrument developed by SUMI (Software Usability Measurement Inventory) evaluation. The SUMI is a reliable method for assessing the quality of use of software products. It is supported by an extensive reference database embedded in an effective analysis and report generation tool; it has been developed, validated and standardized on an international basis.

External dimension items to measure the systemic level factors comprises social, culture, economic, historical, physical and technological. The systemic level roughly matches the external dimension of Roger's attributes were adapted from Moore, Benbasat, (1991) is general enough to be used with modification for the type of innovation being studied. 
Rogers (1995) acknowledged the work done by Moore, Benbasat, (1991) and agreed that the items can be applied to any particular innovation.

\section{Pre-Test and Pilot Study}

First step: it was decided to organize a session of seven under-graduate students asking them to complete a self-administrated questionnaire. Subsequently, participants were asked for comment and give any feedback on the instrument concerning any unclear wording or vagueness. Besides, the pilot testing aimed to guesstimate the time required to complete the questionnaire. Because some minor modifications were made with pilot testing, but in the main questions and instructions were found to be satisfactory. The middling time of completing the questionnaire was from twenty to twenty five minutes, which was considered a reasonable time.

Second step: a literature review was performed to launch an appropriate sample size for the pilot test. According to Denscombe (2010) suggests that for small-scale data collection the sample should contain thirty to two hundred responses. However and Oates (2005) states that researchers should have a sample that involves at least thirty responses for small-scale projects. Besides, he argues that a sample fewer than this may effect in the analysis becoming unreliable.

Based on these suggestions of prior studies, the current research succeeded in having thirty three usable observations from students at DMU. The aim of this stage was to check the reliability of its instrument and prove its clearness and the meaningfulness of its items. The accepted cut-off value for reliability should be equal or greater than 0.50 or above 0.70 . Results showed all the constructs exceeded the threshold value of 0.70 , except friend influence and self-efficacy, which scored 0.66 and 0.64 respectively, which is still considered an adequate level of reliability. Consequently, it can be confirmed that the instrument is reliable and ready for the main study.

\section{THE CONFIRMATORY STUDY}

\section{Data Collection}

There are four parts in the questionnaire; part A, respondents were ask to rate their perception, about IME usage, that is relative to individual using five point Likert scale. The statements are derived from the 3P model created by Biggs and Moore (1993) and include other items as well from Moore and Benbasat (1991). There are three categories of questions: Presage (15 measure), Process (5 measures) and Product (3 measures). Meanwhile in part $B$, respondents were ask to rate their opinion about pedagogical strategies. In part $C$, respondents were ask to rate their perception about systemic level of IMEE using Likert scale ranging from 1-point (strongly disagree) and 5-point (strongly agree). Finally, the research surveyed other important issues such as participant demographics in part D was used to collect demographic information such as gender, age, mode of study, highest level of education, and academic specialization. The data collection was performed using special Internet-based software called "Survey" owned and operated by Kokteyl, Inc (http://www.surveey.com/survey/Communication.aspx). This software is frequently used in various kinds of research and for data gathering activities. The questionnaire is first created with the "Form Editor" software and then an E-Mail describing the nature of the study with an Internet link to the actual questionnaire was sent to the respondents as well as given some questionnaire to volunteer students. 


\section{Model Estimation}

The Partial Least Squares algorithm was used as the method of estimation and the major analytical tool in this study. As the model involves hierarchical higher order constructs, viz. communication and mediation, the two-steps approach ( Agarwal \& Karahanna, 2000; Henseler, et.al, 2007) to modelling higher order latent variables in the context of PLS modeling was favored over the more common hierarchical components approach (also dubbed repeated indicators approach inasmuch as the latter was shown to yield biased and less consistent estimates (especially in the case of small samples) with respect to the former (Wilson, Henseler, 2007).

\section{Principal Components Analysis}

The PCA of mediation indicators was carried out with the software SPSS 18. The Kaiser criterion pointed to a three-component solution, rotated obliquely with the Promax algorithm.

Table: 2

Pattern matrix of the Principal Components Analysis of the Mediation construct items

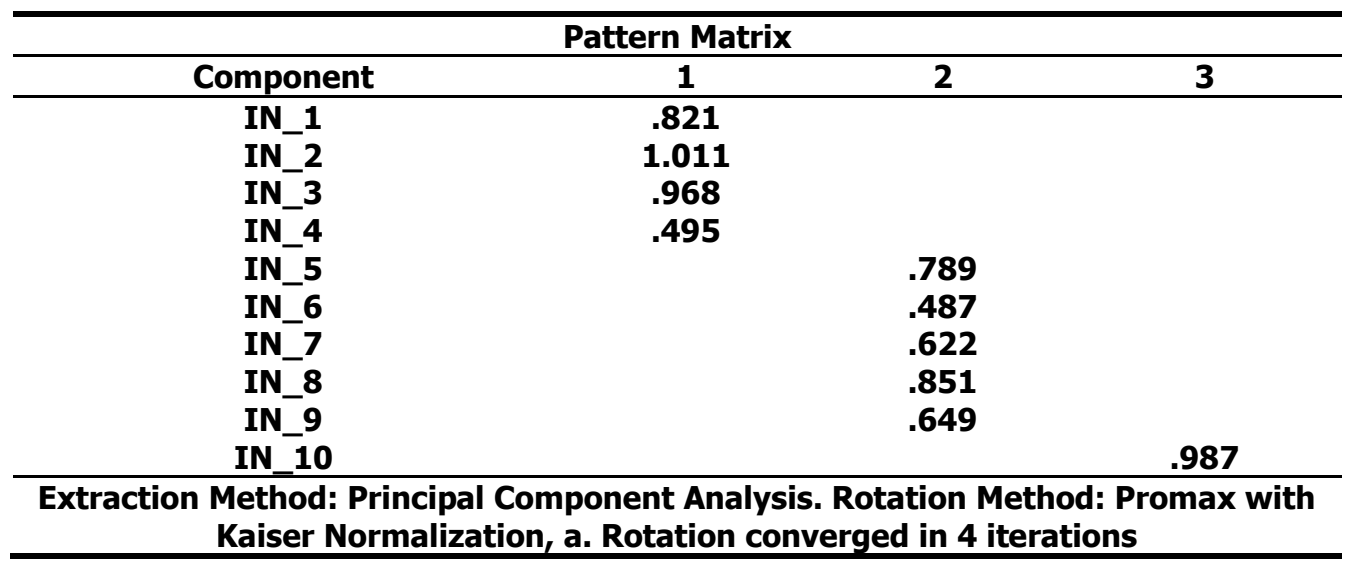

As evidenced in the pattern matrix reported in Table 2, the first component is correlated with the first four items while the third one is formed by the sole IN_10 variable. In the three-componential space, the communality of IN_9 is quite low thereby betraying insufficient quality of representation. Moreover, the loading of IN_4 onto the first component is on the verge of practical significance with respect to sample size. However, the items were not removed because the more cogent PLS estimation verdict is pending.

\section{PLS Estimation of Mediation Model 1}

First step: The estimated model was a model wherein only first-order constructs were specified. Thus, instead of being regressed on the second-order constructs, namely communication and mediation, the dependent constructs were regressed on the first-order dimensions thereof. The estimation was carried out using the Partial Least Squares (PLS) Algorithm with the centroid weighting scheme inasmuch as it proved to be best suited for the detection of small effects purportedly involved in the two rival research models to be estimated, especially moderation effects and, to a lesser extent, indirect effects. The measurement mode was specified as reflective (mode A) within all blocks, as the indicators consist of attitudinal data. The package plspm of the $R$ software environment was used for the purposes of the first-step estimation because of the data management facilities, while the SmartPLS software was used during the second step on account of its moderation effects utilities. 
Table: 3

Psychometric properties of the original latent variables in the first-stage estimation

\begin{tabular}{ccccc}
\hline & C.alpha & DG.rho & eig.2nd & AVE \\
\hline SI & 0.394 & 0.670 & 1.009 & 0.532 \\
TI & 0.230 & 0.599 & 0.882 & 0.612 \\
CI & 0.300 & 0.617 & 0.999 & 0.462 \\
VI & 0.204 & 0.715 & 0.887 & 0.516 \\
TR & 0.441 & 0.725 & 0.937 & 0.469 \\
RA & 0.705 & 0.772 & 2.273 & 0.345 \\
PRI & 0.510 & 0.756 & 0.993 & 0.405 \\
PRE & 0.000 & 0.399 & 0.893 & 0.548 \\
IC & 0.686 & 0.793 & 1.096 & 0.439 \\
LT & 0.487 & 0.796 & 0.678 & 0.661 \\
POLE & 0.799 & 0.855 & 1.116 & 0.464 \\
ADOPTE* & 1.000 & 1.000 & 0.000 & 1.000 \\
GOF & \multicolumn{3}{c}{0.468} \\
\hline *The psychometric properties could not be assessed because the measurement \\
model parameters were fixed for identification purposes. \\
\hline \multicolumn{5}{c}{}
\end{tabular}

Table 3 displays the psychometric properties of the original latent variables in the first-stage estimation. The first-step estimation results show that some constructs cannot boast acceptable psychometric properties. More specifically, the blocks SI, TI, CI, VI, TR, RA, PRI, PRE, IC, LT and POLE are shown to be deficient in terms of reliability (as measured by coefficient Cronbach alpha (Must be greater than 0.7.) and coefficient rho of Dillon-Goldstein(Must be greater than 0.6 ), validity (assessed by the Average Variance Extracted, herein AVE (Must be greater than 0.5)) and/or unidimensionality (appraised through the second Eigen value (Must be smaller than 1 and possibly much smaller that the first one) of the spectral analysis).

In order to gauge the extent to which the inverse items are the source of the above mentioned psychometric defects, Table 4 exhibits the loadings of the original items, as well as their standard errors and $95 \%$ confidence intervals obtained through resembling (bootstrap 1000 replications).

Table: 4

Estimates, standard errors and t-statistics of total effects

\begin{tabular}{|c|c|c|c|c|c|}
\hline & Original & Mean.Boot & Std.Error & perc.025 & perc.975 \\
\hline SI_3 & -0.233 & -0.210 & 0.223 & -0.583 & 0.243 \\
\hline TI_3 & -0.469 & -0.454 & 0.162 & -0.716 & -0.090 \\
\hline CI_3 & -0.437 & -0.270 & 0.466 & -0.819 & 0.912 \\
\hline RD_4 & 0.571 & 0.574 & 0.087 & 0.398 & 0.733 \\
\hline VI_1 & 0.215 & 0.222 & 0.400 & -0.596 & 0.888 \\
\hline VI_2 & 0.995 & 0.889 & 0.237 & -0.104 & 1.000 \\
\hline TR_3 & 0.124 & 0.163 & 0.429 & -0.706 & 0.899 \\
\hline RA_1 & 0.153 & 0.122 & 0.255 & -0.421 & 0.577 \\
\hline RA_2 & 0.085 & 0.057 & 0.248 & -0.444 & 0.507 \\
\hline RA_3 & 0.353 & 0.322 & 0.210 & -0.144 & 0.653 \\
\hline RA_8 & 0.577 & 0.558 & 0.121 & 0.281 & 0.764 \\
\hline PRI_1 & -0.041 & 0.101 & 0.433 & -0.620 & 0.907 \\
\hline PRI_2 & 0.444 & 0.438 & 0.292 & -0.202 & 0.863 \\
\hline PRI_3 & 0.986 & 0.746 & 0.426 & -0.662 & 0.996 \\
\hline PRE_1 & 0.764 & 0.451 & 0.569 & -0.750 & 0.890 \\
\hline PRE_2 & 0.832 & 0.473 & 0.619 & -0.800 & 0.920 \\
\hline PRE_3 & 0.687 & 0.377 & 0.525 & -0.706 & 0.811 \\
\hline PRE_4 & -0.904 & -0.371 & 0.733 & -0.926 & 0.968 \\
\hline PRE_5 & -0.284 & -0.091 & 0.453 & -0.703 & 0.807 \\
\hline IC_ $\overline{1}$ & 0.763 & 0.626 & 0.325 & -0.390 & 0.944 \\
\hline IC_2 & 0.838 & 0.674 & 0.276 & -0.201 & 0.903 \\
\hline IC_3 & 0.764 & 0.619 & 0.298 & -0.307 & 0.901 \\
\hline IC_4 & 0.686 & 0.557 & 0.229 & -0.082 & 0.815 \\
\hline IC_5 & 0.500 & 0.418 & 0.291 & -0.358 & 0.796 \\
\hline IC_6 6 & 0.007 & -0.001 & 0.260 & -0.535 & 0.497 \\
\hline POLE_1 & 0.549 & 0.538 & 0.103 & 0.308 & 0.713 \\
\hline POLE_2 & 0.446 & 0.436 & 0.124 & 0.173 & 0.658 \\
\hline
\end{tabular}


Table 4 confirms that the inverse items are fraught with problems. Not only are not they, for most cases, statistically significant (the confidence interval does contain zero), but they also have the wrong sign (even after reverse coding) or propagate a negative sign to other items pertaining to the same scale. In the rare cases where such problems are not evinced, the inverse items are part of a block that is not unidimensional and/or have loadings that are not large enough to achieve validity. Thus, it seemed inevitable that the inverse items should be removed. Hence, the pool of weeded items is comprised of: SI_3, TI_3, CI_3, RD_4, VI_2, TR_3, RA_1, RA_2, RA_3, RA_8, PRI_1, PRE_4 PRE_5, IC_6, IC_5,POLE_7, POLE_1, and POLE_2.

Table: 5

Correlations between latent variables

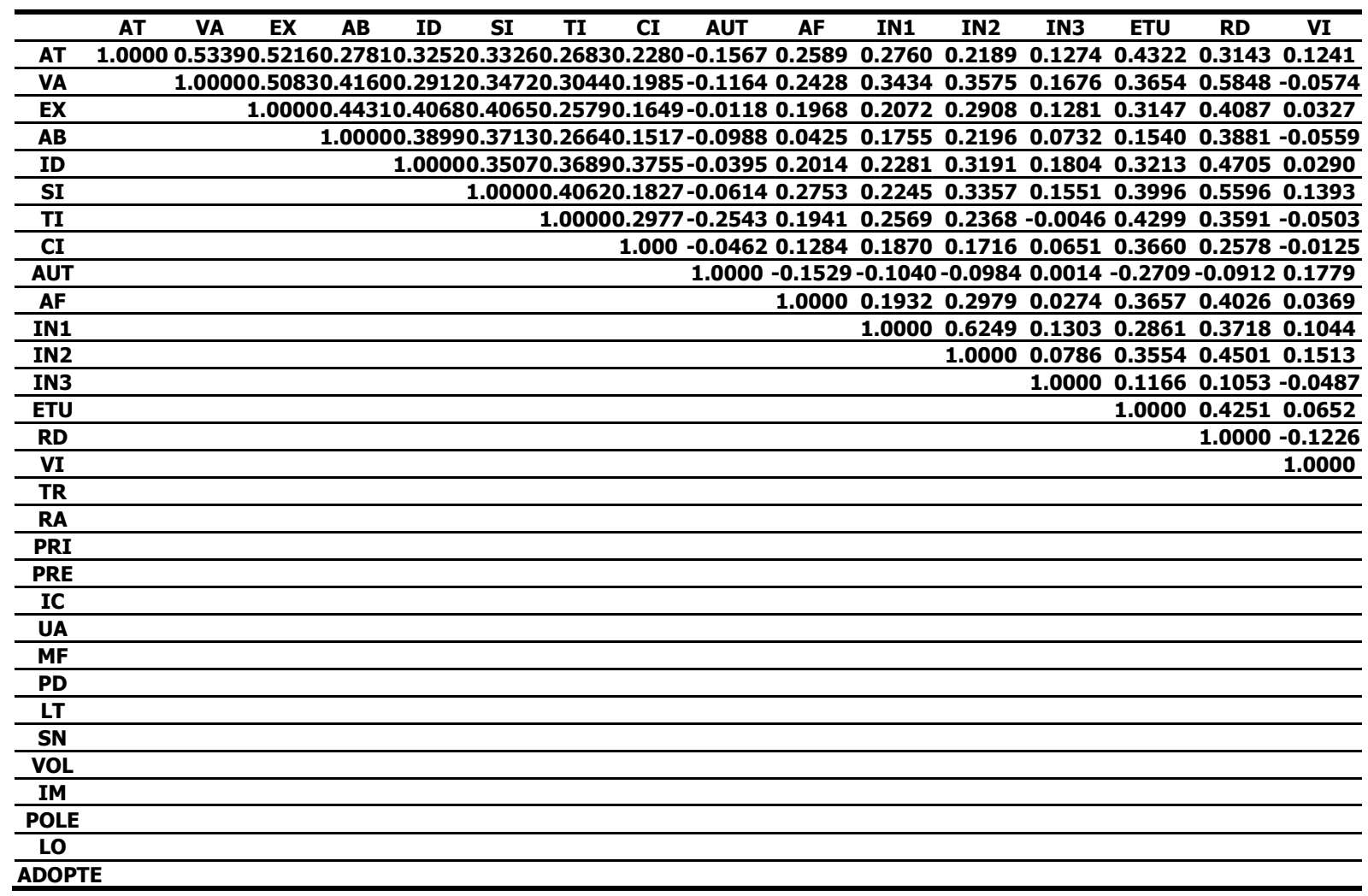

As for discriminate validity, Table 5 reports the correlations between latent variables. It can be verified that for each blocks all correlations are smaller than the square root of the AVE.

According to the Fornell and Larcker criterion, discriminate validity is accredited. Furthermore, it is noteworthy that intercorrelations between first-order dimensions of communication and mediations are not high enough to warrant a reflective mode for the second-order constructs in the second step. That is why the formative mode (Mode B) will be specified for mediation and communication in the second step.

Second step: The partial mediation model M1 was estimated using PLS. The scores of the first-order dimensions of the Communication and Mediation constructs, calculated from the first step, were used as the indicators thereof. The reflective measurement mode (mode A) was specified for all blocks except Communication and Mediation for the reason stated above. The path coefficients, representing the hypothesized direct effects, are reported in Table 6, together with their standard errors and associated t-statistics obtained through resembling (bootstrap 1000 replications). Bidirectional significance tests were used for the sake of testing statistical significance. Coefficients significant at the $5 \%$ level are marked with double asterisks while coefficients significant at the $10 \%$ level are marked with an 
asterisk. Furthermore, direct effects that are either statistically significant or on the verge of statistical significance are highlighted in bold.

It appears from Table 6 that amongst the hypothesized effects on POLE, only the effects of COM, MF and VI are statistically significant (at the $5 \%$ conventional level). Although they did not achieve formal statistical significance, the effects of PRI and MED are roughly significant at the $10 \%$ level. Therefore, MED and PRI can be considered salient predictors of POLE, since augmenting the bootstrap replications is likely to reduce the standard errors of their effects, thereby conducting to their achieving statistical significance. All salient effects are positive and moderate in magnitude (ranging between 0.15 and 0.30 ), except for MF whose effect is negative. In turn, POLE exerts a significant moderate positive impact on LO, together with COM, LT and VA. Finally, LO AF and ID positively and significantly affect ADOPTE, whereas TR influences it negatively.

With respect to the partial mediation theory underlying Model 1, it is noteworthy that POLE affects LO, which in turn affects ADOPTE, whereas POLE does not affect ADOPTE directly. This allows us to conjecture that LO may mediate completely mediate the effect of POLE on ADOPTE and that POLE may not only mediate the effects on LO but also the impacts on ADOPTE. Such conjectures needs further evidence to be sought in the subsequent analysis.

In order to check the plausibility the hypothesis of the meditational role of POLE underpinning Model M1, Table 6 reports estimates, standard errors and t-statistics of total effects. Total effects that are significant at the $5 \%$ level are marked with double asterisks while those significant at the $\mathbf{1 0 \%}$ level are marked with an asterisk. Furthermore, total effects that are either statistically significant or on the verge of statistical significance are highlighted in bold.

Table: 6

Estimates, standard errors and t-statistics of path coefficients

\begin{tabular}{clccc}
\hline Direct Effect & Original Sample & Sample Mean & Standard Error & T-statistic \\
\hline AF -> ADOPTE & $0.286958 * *$ & 0.297984 & 0.097675 & 2.937899 \\
COM -> LO & $0.180605 *$ & 0.173858 & 0.098518 & 1.833221 \\
COM -> POLE & $0.252091 * *$ & 0.260096 & 0.114559 & 2.200531 \\
ID -> ADOPTE & $0.298647 * *$ & 0.296808 & 0.107743 & 2.771847 \\
LO -> ADOPTE & $0.312112 * *$ & 0.313976 & 0.121595 & 2.566824 \\
LT -> LO & $0.137541 *$ & 0.137153 & 0.070873 & 1.940665 \\
MED -> POLE & 0.141123 & 0.135271 & 0.091587 & 1.540871 \\
MF -> POLE & $-0.208727 * *$ & -0.194153 & 0.089334 & 2.336467 \\
POLE -> LO & $0.245396 * *$ & 0.242285 & 0.089546 & 2.740440 \\
PRI -> POLE & 0.143595 & 0.132979 & 0.092597 & 1.550762 \\
TR -> ADOPTE & $-0.173790 *$ & -0.162253 & 0.103677 & -1.676265 \\
VA -> LO & $0.245495 * *$ & 0.245400 & 0.102546 & 2.393997 \\
VI -> POLE & $0.169023 * *$ & 0.154694 & 0.082590 & 2.046531 \\
\hline
\end{tabular}

Table 7 reports estimates, standard errors and t-statistics of total effects. Total effects that are significant at the $5 \%$ level are marked with double asterisks while those significant at the $10 \%$ level are marked with an asterisk. Furthermore, total effects that are either statistically significant or on the verge of statistical significance are highlighted in bold. To assess the partial mediation, we ought to focus on the total effects involving the mediation of POLE. In this respect, Table 7 shows that the total effects of COM, LT, VA and VOL on LO are either significant or on the verge of significance. Besides, these total effects are different from the associated direct effects. Consequently, POLE can be said to mediate the impacts of COM, LT, VA and VOL on LO. In the case of VOL mediation is complete since VOL does not influence LO directly. Likewise, while POLE does not influence ADOPTE directly, its total effect thereon is significant at the $10 \%$ level, which vouches for the complete mediation role of $L O$ in the relationship between POLE and ADOPTE, since POLE influences LO which influences ADOPTE. As a consequence of POLE influencing ADOPTE indirectly, not only does POLE mediate the effects between external, internal and pedagogical factors on 
LO, but it also mediates their impacts on ADOPTE. Thus, it should come as no surprise that the total effects of AF, ID, TR and VA on ADOPTE are significant and different from the associated direct effects. Hence the mediation role of POLE in these relationships, mediation being complete in the latter case.

Table: 7

Estimates, standard errors and t-statistics of total effects

\begin{tabular}{clccc}
\hline Total Effect & Original Sample & Sample Mean & Standard Error & T-statistic \\
\hline AF-> ADOPTE & $0.263951 * *$ & 0.277904 & 0.098332 & 2.684277 \\
COM -> LO & $0.242468 * *$ & 0.236344 & 0.094069 & 2.577544 \\
COM-> POLE & $0.252091 * *$ & 0.260096 & 0.114559 & 2.200531 \\
ID -> ADOPTE & $0.287618 * *$ & 0.289545 & 0.112151 & 2.564561 \\
LO-> ADOPTE & $0.312112 * *$ & 0.313976 & 0.121595 & 2.566824 \\
LT -> LO & $0.133483 *$ & 0.134554 & 0.070386 & 1.896430 \\
MF-> POLE & $-0.208727 * *$ & -0.194153 & 0.089334 & 2.336467 \\
POLE-> ADOPTE & $0.159845 *$ & 0.166473 & 0.089606 & 1.783861 \\
POLE -> LO & $0.245396 * *$ & 0.242285 & 0.089546 & 2.740440 \\
TR -> ADOPTE & -0.174922 & -0.170102 & 0.108583 & 1.610956 \\
VA -> ADOPTE & 0.190580 & 0.167116 & 0.120316 & 1.583990 \\
VA -> LO & $0.284504 * *$ & 0.285792 & 0.114240 & 2.490404 \\
VI -> POLE & $0.169023 * *$ & 0.154694 & 0.082590 & 2.046531 \\
VOL -> LO & 0.123107 & 0.137117 & 0.078024 &
\end{tabular}

PLS Estimation of Moderation Model 2

First step: the first step estimation of model 2 proceeded analogously with model 1 and yielded similar conclusions in terms of reliability, unidimensionality, convergent validity and discriminant validity. As a consequence, there is little use reproducing the results of the first step herein.

The only difference between the twain models lies in the specification. In fact, moderating effects were estimated based on the product indicator approach proposed by Chin, et.al, (1996) [22]. According to this approach, the moderating effect of a latent variable $Z$ on the impact of an independent latent variable $X$ on a latent dependent variable $Y$ consists of the effect on $Y$ of a latent interaction variable equivalent to a created latent variable made up of the product of $X$ and $Z$. Using the standardized indicators of the predictor variable (i.e., $X$ ) and the moderator variable (i.e., $Z$ ), product indicators are then developed by creating all possible products from the two sets of indicators. These product indicators are used to reflect the latent interaction variable. Hence, specification of latent interaction variables consisting of products of POLE and all external, internal and pedagogical factors, and the operationalization thereof with all possible products of the indicators of POLE and the indicators of these factors.

Second step: Table 8 reports estimates of paths coefficients specified in model 2 along with their standard errors and associated t-statistics obtained through resampling (bootstrap with only $\mathbf{5 0 0}$ replications do to limitations of available computing power). Path coefficients include both linear and nonlinear effects. Linear effects are the main effects of predictors, whereas nonlinear effects are interaction effects. Bidirectional significance tests were used for the sake of testing statistical significance. Coefficients significant at the $5 \%$ level are marked with double asterisks while coefficients significant at the $10 \%$ level are marked with an asterisk. Furthermore, path coefficients that are either statistically significant or on the verge of statistical significance are highlighted in yellow. It behooved us to consider coefficients that are on the verge of statistical significance, because we reckon that an increase in the number of bootstrap replications would have dwindled their standard errors, thereby rendering them statistically significant. 
Table: 8

Estimates, standard errors and t-statistics of total effects

\begin{tabular}{clccc}
\hline Total Effect & Original Sample & Sample Mean & Standard Error & T-statistic \\
\hline AB $*$ POLE -> LO & $1.126662 *$ & 0.798927 & 0.678663 & 1.660120 \\
AF -> ADOPTE & $0.269265 * *$ & 0.281265 & 0.092077 & 2.924358 \\
AT -> ADOPTE & -0.145152 & -0.154022 & 0.130817 & 1.109585 \\
AT -> LO & 0.386258 & 0.229691 & 0.513810 & 0.751754 \\
AF -> ADOPTE & $0.269265 * *$ & 0.281265 & 0.092077 & 2.924358 \\
ID -> ADOPTE & $0.303455 *$ & 0.309326 & 0.105718 & 2.870422 \\
ID -> LO & $1.063578 * *$ & 0.832283 & 0.551137 & 1.929788 \\
IC -> ADOPTE & -0.128857 & -0.120830 & 0.105287 & 1.223859 \\
ID $*$ POLE -> LO & $-1.992796 * *$ & -1.566847 & 0.931094 & 2.140273 \\
LO -> ADOPTE & $0.325274 * *$ & 0.307028 & 0.123841 & 2.626545 \\
RD -> LO & $-1.625438 *$ & -1.103701 & 0.861728 & 1.886254 \\
RD $*$ POLE -> LO & $2.797140 * *$ & 1.958689 & 1.312358 & 2.131385 \\
POLE -> ADOPTE & 0.082157 & 0.087366 & 0.101457 & 0.809776 \\
SN -> LO & 1.158637 & 0.628762 & 0.750755 & 1.543297 \\
SN $*$ POLE -> LO & -1.924728 & -1.077831 & 1.210962 & 1.589420 \\
TR -> ADOPTE & $-0.183640 *$ & -0.178600 & 0.105691 & 1.737515 \\
VA -> LO & 1.014509 & 0.609143 & 0.631320 & 1.606964 \\
TR -> LO & -0.071104 & -0.138703 & 0.559403 & 0.127108 \\
\hline
\end{tabular}

Table 8 shows that the variables which influence LO directly and linearly are COM and VA. Likewise the variables which influence ADOPTE directly and linearly are AF, ID, TR and LO, with the effect of TR being negative. On the other hand, it turned out that AB, ID, RD and SN exert a nonlinear effect on LO, in the sense that their impact thereon is moderated by POLE.

\section{RESULTS}

As model 1 and model 2 are irreconcilable and imply different managerial recommendations, it is of great import to know which one is more plausible. For want of a formal statistical test allowing to reject one model in favor of the other, as is the case of the likelihood ratio test in the context covariance-based structural equation models, model comparison can be done heuristically, hinging upon goodness of fit indexes meant to reflect the extent to which a model is in accord with the gathered data. The goodness of fit indexes considered herein are the coefficient of determination (R2), the cross-validated communality index and the cross-validated redundancy index.

The coefficient of determination ( $R 2$ or $\mathbf{R}$ square) denotes the proportion of the variance of a dependent variable explained by the independent variables. The cross-validated communality index measures the quality of the measurement model for each block. The cross-validated redundancy index measures the quality of the structural model for each endogenous block, taking into account the measurement model Stone-Geisser's (Q2). Following Wold (1982, 1982, p. 301) the cross-validation test of Stone and Geisser fits soft modeling like hand in glove. In calculating cross-validated communalities and redundancies, the blindfolding procedure was employed with an omission distance equal to 8 , in line with the recommendations of Herman Wold.

Table: 9

$R$ squares in the two rival models

\begin{tabular}{ccc}
\hline R2 & Model 1 & Model 2 \\
\hline ADOPTE & 0.252274 & 0.254049 \\
LO & 0.548840 & 0.692682 \\
POLE & 0.314662 & n.a.* \\
\hline Not applicable because POLE is not a dependent variable in Model 2
\end{tabular}

Table 9 reports $r$ squares in the two rival models. It reveals that while the two models explain quite the same amount of variance of ADOPTE (which should come as no surprise 
since this dependent variables is regressed on the same predictors in both models), model 2 explains a fairy greater proportion of the variance of LO than its counterpart. Hence the superiority model $\mathbf{2}$ in terms of explanatory power.

Table: 10

Cross-validated redundancies in the two rival models

\begin{tabular}{ccc}
\hline Cross-validated redundancy & Model 1 & Model 2 \\
\hline ADOPTE & -0.082926 & 0.262926 \\
LO & 0.290007 & 0.469804 \\
POLE & 0.120539 & n.a.* \\
\hline Not applicable because POLE is not a dependent variable in Model 2 \\
\hline
\end{tabular}

Table 10 reports cross-validated redundancies in the two rival models. Not are the redundancies greater for both LO and ADOPTE in model 2 than their counterparts in model 1 , but the redundancy of ADPTE in model 1 is also negative, which betrays serious problems in terms of goodness of fit.

Table: 11

Cross-validated communalities in the two rival models

\begin{tabular}{|c|c|c|c|c|c|}
\hline $\begin{array}{c}\text { Cross-validated } \\
\text { communality }\end{array}$ & Model 1 & Model 2 & $\begin{array}{c}\text { Cross-validated } \\
\text { communality }\end{array}$ & Model 1 & Model 2 \\
\hline $\begin{array}{c}\text { AB } \\
\text { ADOPTE }\end{array}$ & $\begin{array}{c}0.294768 \\
-\end{array}$ & $\begin{array}{l}0.641981 \\
0.991880\end{array}$ & $\begin{array}{l}\text { MF } \\
\text { PD }\end{array}$ & $\begin{array}{c}- \\
0.329473\end{array}$ & $\begin{array}{l}1.000000 \\
0.766370\end{array}$ \\
\hline $\begin{array}{l}\text { ADOPTE } \\
\text { AF }\end{array}$ & $0 . \overline{304058}$ & $\begin{array}{l}0.991880 \\
0.535982\end{array}$ & $\begin{array}{l}\text { PD } \\
\text { POLE }\end{array}$ & $\begin{array}{l}0.329473 \\
0.287227\end{array}$ & 0.293249 \\
\hline AT & 0.341532 & 0.595104 & PRE & 0.424658 & 0.741299 \\
\hline COM & 0.087836 & 0.422717 & PRI & -0.000000 & 1.000000 \\
\hline ETU & 0.387036 & 0.639405 & RA & 0.368129 & 0.610697 \\
\hline EX & 0.276552 & 0.558185 & RD & 0.495589 & 0.757012 \\
\hline IC & 0.319316 & 0.575100 & SN & 0.295914 & 0.580992 \\
\hline ID & 0.270021 & 0.513037 & TR & 0.114458 & 0.685941 \\
\hline IM & 0.560744 & 0.786703 & UA & 0.332386 & 0.529916 \\
\hline LO & 0.379699 & 0.678124 & VA & 0.438966 & 0.663826 \\
\hline LT & 0.054692 & 0.659650 & VI & - & 1.000000 \\
\hline MED & 0.088431 & 0.497801 & VOL & 0.284800 & 0.778442 \\
\hline
\end{tabular}

Table 11 reports cross-validated communalities in the two rival models. It reveals that the cross communalities for all latent variables are greater, sometimes by far, in model 2 than their counterparts in model 1. Thus, it appears that model 2 outperforms model 1 in terms of all goodness-of-fit criteria. Model 2 can therefore be said to provide a better fit to the data than model 1 . As a result, it can be concluded that in the relationship between external, internal and pedagogical factors and LO, POLE is a moderator rather than a mediator.

\section{CONCLUSION AND FUTURE WORK}

While we used a combination of extended frameworks in this research, the interesting results were found about the research framework that combines the modified innovation diffusion theory (IDT) in conjunction with modified version of the Biggs and Moore model both in the earlier study in addition to this research.

The current research activity been extend the study of e-learning by concentrating on learning where mixed modes were taken into account. In addition a mixture of types of technological software solutions for interactive multimedia and e-learning were investigated (e.g. Wikis, Blogs, Skype). In other words, does the use of interactive multimedia and e-learning tools moderate the presage and learning outcome relationship?

As indicate the students in this research were undergraduate and graduate students experiencing their perspective of interactive multimedia and e-learning environment. 
Hence it would be interesting to examine and test the role of moderating interactive multimedia and e-learning in the extended framework when the undergraduate and graduate students have more experience with interactive multimedia and e-learning.

\section{BIODATA and CONTACT ADDRESSES of the AUTHORS}

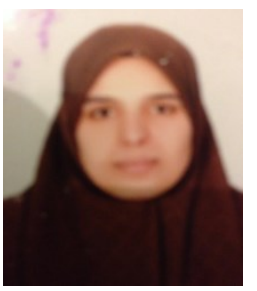

Fathia LAHWAL is PhD Student in STRL De Montfort University, United Kingdom, at College of Computing. Her department is Software Technology Research Laboratory. Her research areas are multimedia and e-learning services.

Fathia LAHWAL

Software Technology Research Laboratory (STRL)

De Montfort University, Leicester, United Kingdom

Phone: +447453510579

e-Mail: fathia272002@yahoo.co.uk

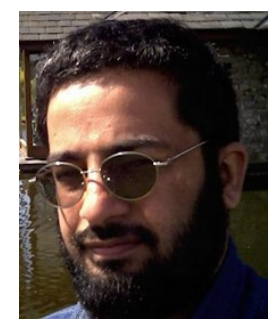

Ajlan S. AL-AJLAN is Assistant Professor of management information system. His position is Vice-Dean of Academic Affairs at the College of Computer, Qassim University, Saudi Arabia. He finished his Ph.D. De Montfort University, United Kingdom. His teaching areas are management information systems, e-leaning systems (Moodle), distance learning, introduction to technology, information technology, decision support system and intelligent system. His research areas are e-leaning, distance learning, strategy of e-learning, digital watermarking, multimedia application, watermarking technology, web services.

Ajlan S. AL-AJLAN

College of Business \& Economics,

Qassim University,

Buraidah, Saudi Arabia,

Phone: +966550856741

e-Mail: ajlan2010@gmail.com

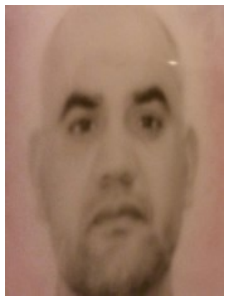

Mohamad AMAIN is PhD Student in STRL De Montfort University, United Kingdom, at College of Computing. His department is Software Technology Research Laboratory. His research areas are information technology, project management, risk management, human resources, human development, economy planning, research methodologies, action research, e-learning and media.

Mohamad AMAIN

Software Technology Research Laboratory (STRL)

De Montfort University, Leicester, United Kingdom

Phone: +447969972956

e-Mail: mohamed372005@yahoo.co.uk 


\section{REFERENCES}

Agarwal, R. \& Karahanna, E. (2000) Time Flies When You're Having Fun: Cognitive Absorption and Beliefs about Information Technology Usage. MIS Quarterly, 24(4), pp. 665-694.

Al-Zoubi, A. et al., (2011) E-learning adoption among adult workers in Jordan. Academic Research International Journal, 1(2), pp 354-374.

Biggs, J. and Moore, P. (1993). The Process of Learning. 3rd ed., Australia: Prentice Hall.

Chin, W. et al., (1996) A Partial Least Squares Latent Variable Modeling Approach For Measuring Interaction Effects: Results From A Monte Carlo Simulation Study And Voice Mail Emotion/Adoption Study. Proceedings of the Seventeenth International Conference on Information Systems. Cleveland, Ohio.

Debevc, M. \& Bele, J. (2008) Usability testing of e-learning content used in two learning management systems, Eurodl. Retrieved February 11, 2016 from http://www.eurodl.org/ materials/contrib/2008/Debevc_Bele.htm

Denscombe, M. (2010) The Good Research Guide: For Small-scale Social Research Projects, 4th ed., UK: Open University Press.

Duan, Y. et al., (2010) A study on e-learning take-up intention from an innovation adoption perspective: A case in China. Journal of Computers \& Education. 55(1), pp. 237-246.

Haverila, M. (2010) Factors affecting new product success in technology companies: the Case of Finland. International Journal of Product Development, 12 (2), pp. 176198.

Haverila, M. \& Barkhi, R. (2009) The influence of experience, ability and interest on elearning effectiveness, European Journal of Open Distance and Learning, 7 (1),pp.1-13.

Heilesen, S. \& Josephsen, J. (2008) E-learning between augmentation \& disruption. Journal of computer and Education, 50(2), pp.525-534.

Henseler, J. et al., (2007) Investigating the moderating role of fit on sports sponsoring and brand equity: a structural model. International Journal of Sports Marketing and Sponsorship, 8 (4), pp. 321-329.

Hsiu-Li Liao. et al., (2008) The role of experience and innovation characteristics in the adoption and continued use of e-learning websites, Computers \& Education, 51(4), pp. 1405-1416.

Inayatullah, S. (2003) Ageing: Alternative futures and policy choices. Foresight Journal, 5(6), pp. 8-17.

Liaw, S. (2008) Investigating students' perceived satisfaction, behavioral intention, and effectiveness of e-learning. Journal of Computers \& Education, 51(2), pp. 864873.

Liu, H. et al., (2009) Impact of media richness and flow on e-learning technology acceptance. Journal of Computers and Education, 52(3), pp: 599-607. 
Moore, C. \& Benbasat, I. (1991) Development of an Instrument to Measure the Perceptions of Adopting an Information Technology Innovation. Information Systems Journal, 3(2), pp. 192-222.

Oates, B. (2005) Researching Information Systems and Computing. 1st ed, UK: Sage Publications.

Rogers, M. (1995) Diffusion of Innovations. 3rd ed., New York, NY: Free Press.

Roca, J. et al., (2006) Understanding e-learning continuance intention: An extension of the Technology Acceptance Model. International Journal of Human-Computer Studies, 64(8), pp. 683-696.

Ryberg, T. (2007) Patch working as a Metaphor for Learning - Understanding youth, learning and technology. Thesis, Aalborg University,

Sanchez, R. \& Hueros, A. (2010) Motivational factors that influence the acceptance of Moodle using TAM. Computers in Human Behavior Journal, 26(6), pp. 1632-1640.

Wilson, B. \& Henseler, J. (2007) Modeling reflective higher-order constructs using three approaches with PLS path modeling: a Monte Carlo comparison. In Conference proceedings ANZMAC, pp.791-800. 